\title{
Cognitive and Emotional Symptoms in Patients with Parkinson's Disease
}

\author{
Julio López Argüelles*1, Lic Aleima B Rodriguez Carbajal ${ }^{1}$ and Dra Leydi M Sosa Aguila ${ }^{2}$ \\ ${ }^{1}$ Department of Neurology, University Hospital Gustavo Aldereguía Lima, Cuba \\ ${ }^{2}$ Department of Genetic, University Hospital Paquito González Cueto, Cuba
}

*Corresponding author: Julio López Argüelles, Neurology Department, University Hospital Gustavo Aldereguía Lima, Cienfuegos, Cuba.

Received Date: October 02, 2019

Published Date: October 14, 2019

\begin{abstract}
Parkinson's disease is the second most frequent degenerative disease of the central nervous system, characterized, by medicine, for a long time as an eminently motor disease. Parkinson's disease also has non-motor symptoms such as emotional and cognitive disorders, associating the cognitive deterioration that can arrive at dementia. Objective: describe the principal cognitive and emotional symptoms of the patients with Parkinson's disease. Parkinson's disease has stopped being recognized as a motor disease exclusively; in addition get involved emotional and cognitive alterations that can be presented in isolation or multiple, with a performance that extends from the normalcy up to dementia.
\end{abstract}

Keywords: Parkinson's disease; Dementia; Emotional; Depression; Cognitive

\section{Introduction}

The non-motor disorders of Parkinson's disease (PD) include all those disorders that are not motor symptoms: neuropsychiatric disorders and of the behavior (dementia, depression, anxiety, psychosis), autonomic (postural hypotension, gastrointestinal and genitourinary disorders, and diaphoresis), sleep disorders, sensitive-motors (fatigue, restless legs syndrome). The pain is a very prevalent symptom in $\mathrm{PD}$, being very important its identification and typing for a correct treatment [1]. The hyposmia is a very frequent symptom that could be utilized as early marker in PD. Various visual and auditory alterations should be taken into account also in the patients with PD [2,3].

Although the motors symptoms are the most notable and principal in $\mathrm{PD}$, every time is paid more attention to the existence of a parallel series of emotional and cognitive disorders even dementia.

\section{Discussion}

\section{Emotional alterations in parkinson's disease}

Depression is a common problem and can appear in early stage of the disease, even before other symptoms are noticed. Depression may not be severe but can intensify it consumption of the PD drugs utilized to treat other symptoms. Fortunately, depression can be treated successfully with drugs antidepressants, although with certain degree of difficulty then the utilization of these interferes in the metabolism of the neurotransmitters involved in the disease which means that the improvement of these mental symptoms upon treating them could worsen the motor symptoms of the disease [4].

Some people with Parkinson's disease become fearful and insecure. Perhaps they fear not to be able to cope with new situations. They may not wish to travel, go to meetings, or socialize with the friends. Some lose their motivation and become dependent on the members of the family. Others can become irritable and too pessimistic. The type of depression that tend to suffer the patients with EP is greater depression or a dysthymiac disorder accompanied by sleep disorders, fatigue, psychomotor retardation, loss of self-esteem and guilt feelings. Various studies have not found associations between the level of depression and other characteristics of the PD as the age, sex, duration of the disease, motor disability, and cognitive deterioration, what raises the controversy of the pathological basis of the affective disorders in the PD, most frequent in patients with PD of akinetic predominance. A source of confusion is that both PD and depression share common 
clinical features, basically the somatic depression manifestations (psychomotor retardation and sleep disorders) [5].

Los tests que evalúan la depresión en la EP contienen muchos apartados somáticos que incrementan artificialmente la presencia de síntomas depresivos. Dakof y Mendelsohn, en su revisión sobre esta problemática, concluyen que el error de reflejar más un trastorno motor que otro afectivo es común para las escalas de Hamilton, Beck y los criterios DSM-III.

The fact that the patients with EP present more depression that the patients with other equally incapacitating diseases, supports the idea that depression in PD is result of a primary biochemical anomaly and not a secondary reaction to the somatic symptomatology. The anomalies found in studies of regional cerebral blood flow, in addition to the reduction of concentration of 5-hydroxyindolacetic (5-HIIA) in the cerebrosipinal fluid, they aim the existence of degenerative alterations in the mesocorticolimbic dopaminergic system and of disorders in the dorsal raphe [6,7].

\section{Cognitive deterioration in parkinson's disease}

Already from the second half of the XIX has been identified cognitive deficits in Parkinson's disease, certainly less notable and with less global deterioration that in Alzheimer's disease [8], but with senile plates and neurofibrillary injuries between $30-55 \%$ of the cases, associating also cortical cholinergic defects and diffuse bodies of Lewy.

Are patients with isolated cognitive deficits and multiple and the cognitive performance can go from the normalcy up to an advanced degree of dementia? The majority of the patients present a deficit which is executive, isolated, or combined with other cognitive alterations, that it is considered what is most characteristic of the disease, and $20-40 \%$ of affected ended as dementia clinically defined. The presence of mild cognitive impairment in the Parkinsonian patients represents the existence of a high risk of dementia appearance during the disease. The cognitive disorders can escape notice in the initial stage of PD, although they are evident to the neuropsychological evaluation $[9,10]$. The cognitive deterioration constitutes a frequent reason for consultation. In light of its suspicion is compulsory to carry out a correct assessment of the mental state of the person who will include the evaluation of the cognitive capacities and of the executive function, in addition to the assessment of its emotional state. There will be assessed jointly the functional state of the individual who will encompass the personality and its behavior, in addition to the degree of affectation of the instrumental and basic activities of daily life [11].

Exist problems of cognitive nature that are manifested specifically in Parkinson's disease, among which can point out:

1. Stable and/or transitory amnesic syndromes: Occur problems of reduced attention by anxiety or depression states.

2. Acute confusional syndrome or delirium: Is an organic cerebral syndrome that lacks specific etiology, fast beginning, characterized by the simultaneous presence of disorders of the conscience and attention.
3. Aphasia: It is a focal syndrome characterized by alterations in the nomination and/or comprehension.

\section{More important aspects in the cognitive assessment}

Executive function: It concerns a theoretical scheme of ideas, with capacity to describe and evaluate, systematically, a series of human behaviors and their performance, defines to a set of cognitive abilities that permit the anticipation and the establishment of goals, the education of plans and programs, the beginning of the activities, and mental operations, the self-regulation of the tasks and the ability to carry them out efficiently. This function behaves critically affected in the majority of the patients with PD from the initial stages of the disease.

Memory: there is a deterioration in the coding and recovery of the reminders. Visuoespaciales alterations: in PD can be owed to dopaminérgicas deficiencies in points previous of the perceptive process. The presumed loss of serotonergics, cholinergics, glutamatergics, triptaminergics, gabaergics, adrenergic and noradrenergics neurons could respond to the cognitive symptoms, that could be prior to the diagnosis of PD.

\section{Conclusion}

PD has stopped being recognized as a motor disease exclusively, in addition get involved emotional and cognitive alterations that can be presented in isolation or multiple, with a performance that extends from the normalcy up to dementia, involving the disorder of numerous neurotransmitters and central nervous system circuits.

\section{Acknowledgement}

None.

\section{Conflict of Interest}

The author declares there is no conflict of interest.

\section{References}

1. Sung S, Vijiaratnam N, Chan DWC, Farrell M, Evans AH (2018) Parkinson disease: A systemic review of pain sensitivities and its association with clinical pain and response to dopaminergic stimulation. J Neurol Sci 395: 172-206.

2. Rolinski M, Szewczyk Krolikowski K, Tomlinson PR, Nithi K, Talbot K, et al. (2014) REM sleep behaviour disorder is associated with worse quality of life and other non-motor features in early Parkinson's disease. J Neurol Neurosurg Psychiatry 85(5): 560-566.

3. Kurtis MM, Rodriguez-Blazquez C, Martinez-Martin P (2013) Relationship between sleep disorders and other non-motor symptoms in Parkinson's disease. Parkinsonism Relat Disord 19(12): 1152-1155.

4. Dewey RB, Taneja A, McClintock SM, Cullum CM, Dewey RB, et al. (2012) Motor symptoms at onset of Parkinson disease and risk for cognitive impairment and depression. Cogn Behav Neurol 25(3): 115-120.

5. Lenka A, Pagonabarraga J, Pal PK, Bejr-Kasem H, Kulisvesky J (2019) Minor hallucinations in Parkinson disease: A subtle symptom with major clinical implications. Neurology 93(6): 259-266.

6. López Argüelles J, Rodriguez Carbajal A, Gonzalez Alba G, Sosa Aguila LM, Montalvo Manso L (2019) Factors Related with Frontal Dysfunction in Early Stages of Parkinson Disease. J Alzheimers Neurodegener Dis 5: 018.

7. Owens-Walton C, Jakabek D, Li X, Wilkes FA, Walterfang M, et al. (2019) Corrigendum to: "Striatal changes in Parkinson disease: An investigation of morphology, functional connectivity and their relationship to clinical 
symptoms. Psychiatry Res Neuroimaging 286: 76.

8. López-Argüelles J, Sosa-Aguila L, Rodriguez-Carbajal A, Montalvo-Manso L (2019) Progress in knowledge of Alzheimer's disease. Archives in Neurology \& Neuroscience 4(3).

9. Barboza NM, Terra MB, Bueno MEB, Christofoletti G, Smaili SM (2019) Physiotherapy Versus Physiotherapy Plus Cognitive Training on Cognition and Quality of Life in Parkinson Disease: Randomized Clinical Trial. Am J Phys Med Rehabil 98(6): 460-468.
10. De Pablo-Fernandez E, Lees AJ, Holton JL, Warner TT (2019) Prognosis and Neuropathologic Correlation of Clinical Subtypes of Parkinson Disease. JAMA Neurol 76(4): 470-479.

11. Adwani S, Yadav R, Kumar K, Chandra SR, Pal PK (2016) Neuropsychological profile in early Parkinson's disease: Comparison between patients with right side onset versus left side onset of motor symptoms. Ann Indian Acad Neurol 19(1): 74-78. 